\title{
Development and validation of a specific questionnaire to assess health-related quality of life in patients with home enteral nutrition: NutriQoL ${ }^{\circledR}$ development
}

\author{
This article was published in the following Dove Press journal: \\ Patient Preference and Adherence \\ 4 November 2016 \\ Number of times this article has been viewed
}

\author{
Maria Cristina Cuerda \\ Antonio Apezetxea ${ }^{2}$ \\ Lourdes Carrillo ${ }^{3}$ \\ Felipe Casanueva ${ }^{4}$ \\ Federico Cuesta ${ }^{5}$ \\ Jose Antonio Irles ${ }^{6}$ \\ Maria Nuria Virgili ${ }^{7}$ \\ Miquel Layola ${ }^{8}$ \\ Luis Lizan9 \\ 'Hospital General Universitario \\ Gregorio Marañon, Madrid, \\ ${ }^{2}$ Organización Sanitaria Integrada \\ Bilbao Basurto, Bilbao, ${ }^{3}$ Centro de \\ Salud Victoria de Acentejo, Santa \\ Cruz, ${ }^{4}$ Hospital Universitario de \\ Santiago de Compostela, Santiago, \\ ${ }^{5}$ Hospital Clínico San Carlos, Madrid, \\ ${ }^{6} \mathrm{Hospital}$ Universitario Nuestra \\ Señora de Valme, Seville, ${ }^{7}$ Hospital \\ Universitario de Bellvitge, L'Hospitalet \\ de Llobregat, ${ }^{8}$ Nestlé Health Science, \\ Barcelona, 'Outcomes' I0, Universitat \\ Jaume I, Castellon, Spain
}

Introduction: Home enteral nutrition (HEN) is indicated in patients with a functional gastrointestinal tract but who are unable to meet their nutritional requirements with normally consumed foodstuffs. HEN allows patients to remain in their social and family environment, thus reducing complications and costs associated with hospital admission, while increasing health-related quality of life (HRQoL). HRQoL in patients with HEN is mainly evaluated by generic instruments, which are not sensitive enough to identify certain specific patient-related outcomes of HEN.

Objective: To develop a specific instrument to measure HRQoL in patients receiving HEN whose results allow interpretation regardless of the underlying disease and nutritional support administration route: the NutriQoL ${ }^{\mathbb{B}}$ questionnaire.

Materials and methods: The development of the NutriQoL entailed a literature review, focus groups with experts, semistructured interviews with patients, an assessment of face validity and feasibility, and Rasch analysis conducted on data from a sample of 141 patients and 24 caregivers.

Results: Of the 52 items initially proposed on the basis of the literature review, expert focus group, and semi-structured interviews with patients and caregivers, 17 items were finally selected through the development process to make up the final version of the NutriQoL, as well as a visual analog scale for global HRQoL scoring. The selected items were evaluated as adequate for frequency, importance, and clarity. Furthermore, they have been shown to be independent of the underlying condition and HEN administration route.

Conclusion: A new instrument for measuring the HRQoL of patients with HEN in Spain has been developed, whose results are independent of the underlying condition and administration route. The next step will be the validation of the questionnaire to ensure that the instrument is valid, reliable, and sensitive to health status changes in patients, to be used periodically in usual clinical practice.

Keywords: home enteral nutrition, health-related quality of life, questionnaires

\section{Introduction}

Home enteral nutrition (HEN) is a feeding support technique indicated for patients who are unable to meet their nutritional requirements with normally consumed foodstuffs because of their clinical condition (patients with mechanical swallowing or transit disorders, neuromotor disorders, or special energy or nutrient requirements, or severely malnourished patients). ${ }^{1}$ The main purpose of $\mathrm{HEN}$ is to pass adequate nutrients through
Correspondence: Luis Lizan
Outcomes' I0, Universitat Jaume I,

Science, Technology and Business Park, Espaitec 2 Building, Campus of Riu Sec, Avenida Sos Baynat s/n, I207I Castellon, Castellon, Spain

Tel +3496486878I

Email lizan@outcomes 10.com 
the digestive tract using different administration routes and methods in the patient's home. ${ }^{2}$ This intake enables patients to remain in their social and family environment, thus diminishing the likelihood of complications associated with hospital stay, reducing health care costs and increasing health-related quality of life (HRQoL). ${ }^{3}$

HRQoL is a dynamic variable in a person's life history, which evaluates the subjective influence of health status, health care, and preventive health activities on maintaining a level of functioning that makes for general well-being. The fundamental aspects or dimensions of HRQoL are the physical, psychological/cognitive, and social functioning of the individual. Physical aspects include impairment of functions, symptoms, and pain caused by the disease or its treatment; psychological/cognitive aspects cover emotional states and intellectual functions; and social aspects reflect the person's isolation, self-esteem, and social role. ${ }^{4}$

A number of studies on patients receiving HEN, designed to learn about HRQoL, used generic measurement instruments. However, such tools are not sensitive enough to identify the influence of the specifics of HEN on patients. ${ }^{5,6}$ Only one specific HRQoL questionnaire has been described that solely measures the impact of enteral nutrition tubes on patients with head and neck cancer. ${ }^{7}$
The lack of specific questionnaires to measure HRQoL in patients with HEN, and its impact, has highlighted the need to develop the NutriQoL questionnaire, a tool to assess HRQoL in these patients regardless of the underlying disease and the nutrition administration route. ${ }^{7}$

Here, we describe in detail the development of the NutriQoL questionnaire for measuring the HRQoL in Spanish patients receiving HEN regardless of the underlying condition and administration route.

\section{Methods}

\section{Study design}

The NutriQoL was designed in two phases:

- Phase 1. Development of the specific HRQoL questionnaire for patients receiving HEN. This phase consisted of a literature review, focus groups with experts, semistructured interviews with patients and caregivers, assessing face validity and feasibility, as well as the application of Rasch analysis in a pilot study (Figure 1).

- Phase 2. Validation or evaluation of the psychometric properties of the questionnaire. During this phase, we tested for reliability (internal consistency, stability, or test-retest and interobserver agreement), sensitivity to changes, minimal clinically important difference

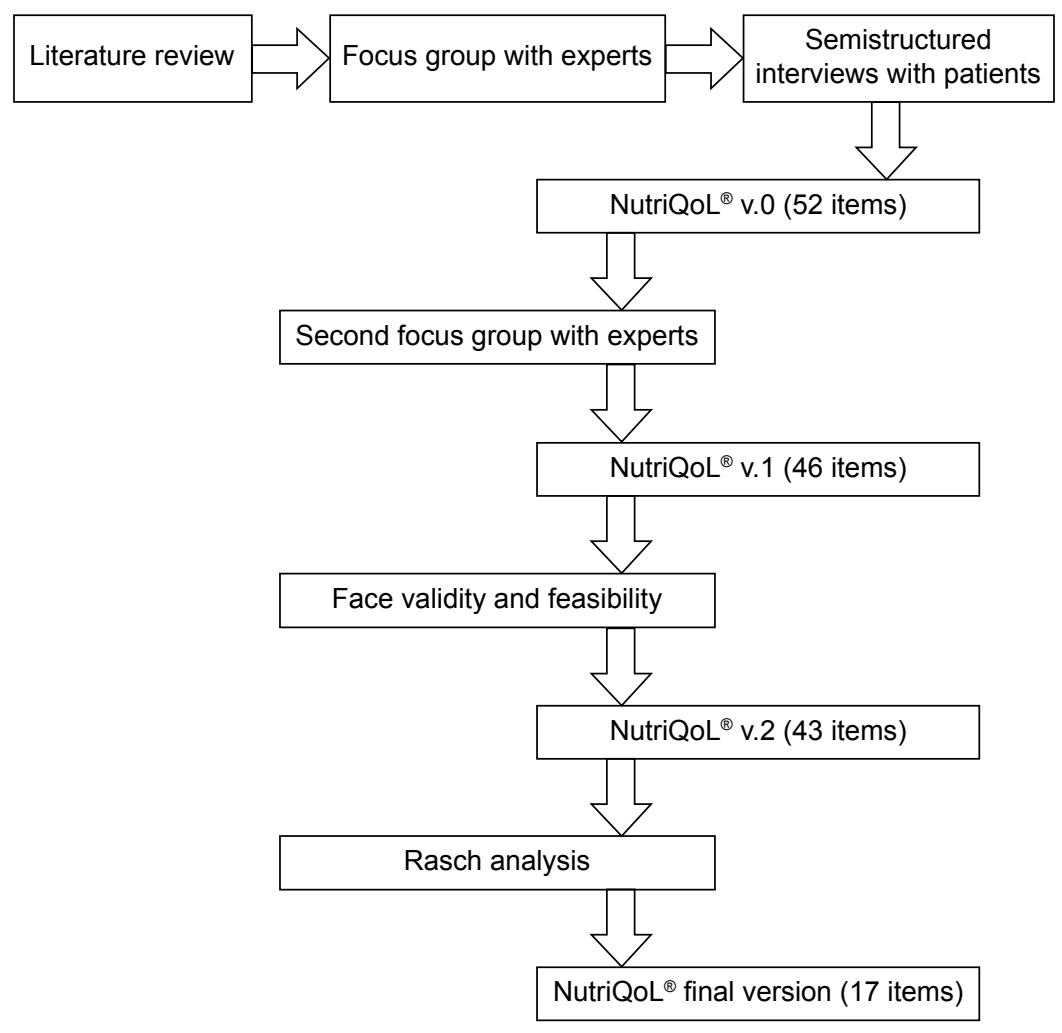

Figure I The NutriQoL ${ }^{\circledR}$ study diagram.

Note: Phase I questionnaire development. 
(MCID), and validity (criterion validity and construct validity).

In this work, we present the questionnaire development methodology (Phase 1).

Different strategies were implemented in order to define the items to be included in the specific HRQoL questionnaire:

\section{Literature review and first focus group with experts}

A literature review was conducted to identify the main dimensions of HRQoL described in this group of patients. Subsequently, a focus group with seven experts with extensive experience in the field of HEN was set up (one general practitioner, two specialists in endocrinology and nutrition, one specialist in geriatrics, two specialists in nutrition and dietetics, and one specialist in domiciliary hospitalization). The purpose of the focus group was to compare the experts' opinions about the dimensions identified in the literature with respect to the HRQoL of patients with HEN and to determine other important aspects that were not identified in the literature. ${ }^{8}$

\section{Semistructured interviews with patients}

Based on the conclusions of the first focus group with experts, a script to be used for semistructured interviews was developed, in order to learn the views of patients and caregivers, and determine additional issues that had not been identified by the experts. ${ }^{9}$

It was assumed that, given the nature of the diseases involved in HEN, there would be some patients who would not be able to complete the questionnaire on their own and would need the help of their caregivers. Furthermore, we thought it would be interesting to collect the views of the primary caregiver, too. Hence, for the interviews, we selected patients and caregivers of patients who had been receiving HEN for at least 3 months, regardless of the underlying disease. This stage enabled us to draw up a first list of items (version 0 of the questionnaire). All participants gave written informed consent to participate in the study.

\section{Second focus group with experts}

Based on this list of items, we set up a second focus group with the same experts who had taken part in the first one to evaluate the items in version 0 of the questionnaire. This evaluation consisted of rating each of the items on a 5-point Likert scale (1= not clear/frequent/important and $5=$ very clear/frequent/important). Participants rated the clarity of the wording, the frequency of occurrence in routine clinical practice for each item, that is, the number of times it is mentioned by patients in the consulting room, and the importance or the degree to which the item affects or modifies the patient's HRQoL from the professional's perspective. $^{10,11}$

For each item, we calculated the average score for each of the mentioned features, attaching greater value to importance and frequency, as clarity could be modified. In the new version of the questionnaire, we only included items that had the following:

- A high score (between 4 and 5) for clarity, frequency, and importance.

- A high score for clarity and importance despite low frequency.

- A high score for frequency and importance with modification of the item wording (low clarity).

After this assessment of the items by the experts, we drew up version 1 of the questionnaire.

\section{Face validity and feasibility}

Face validity measures the degree to which the items included in the questionnaire seem to measure what they purport to measure. It is the simplest method of measuring the validity of the instrument. It is the common sense part of the validity of the questionnaire in which it is ensured that the instrument items are appropriate; that is, they are clear, and that their wording is understood. In addition, it assesses the importance attached to the content of the items and the appropriateness of the response scale used. ${ }^{12}$

Feasibility measures whether the questionnaire is accessible enough to be applied in its intended field. Aspects that are usually evaluated are the time required for completion, the simplicity and harmony of the format, and the overall presentation of the questionnaire. ${ }^{12}$

To assess these properties, and as recommended by the ISPOR PRO Good Research Practices Task Force, ${ }^{13}$ we selected patients who had been receiving HEN for at least 3 months, no matter what the clinical diagnosis was, and who were physically and intellectually able to participate in the interview and answer the questionnaire. Additionally, we also included caregivers aged $\geq 18$ years. All of them consented to participate in the study. Participants quantitatively assessed aspects of the questionnaire's face validity and feasibility, specifically the overall presentation of the questionnaire and the time spent on completing it.

As in similar studies, ${ }^{10}$ we included in the questionnaire the following: the items to which $90 \%$ of participants gave a high score (4 or 5) for importance, frequency, and clarity on a 5-point Likert scale (1= not important/frequent/clear and 
$5=$ very important/frequent/clear); items to which $90 \%$ gave high scores for importance and clarity even when frequency was not highly rated; and items to which $90 \%$ of participants gave high scores for frequency and importance even though clarity did not achieve this figure. If at least $5 \%$ and $25 \%$ of the participants gave negative scores ( 1 and 2 ) to the clarity of an item and the response scale used, respectively, both aspects were modified to make them easier to understand. ${ }^{10}$

As for feasibility, the overall presentation of the questionnaire was adapted when at least $10 \%$ of participants gave a negative score to this aspect. We considered reducing the number of items in the questionnaire if the average response time exceeded 30 minutes. Based on the results, we drew up version 2 of the questionnaire.

\section{Pilot study to perform the Rasch analysis}

A pilot study was designed to perform the Rasch analysis. ${ }^{14}$ We included patients $>18$ years who had been receiving HEN for at least 1 month. If patients did not comply with the selection criteria, the caregiver was invited to respond. All participants answered version 2 of the questionnaire and gave their consent to participate in the study. We analyzed the results using the Rasch model, a mathematical strategy used to develop and evaluate the psychometric properties of measurement instruments. ${ }^{15,16}$

Rasch models ensure that the characteristics of the person parameters and the questionnaire items are independent; that is, each person's estimated ability does not depend on the number and type of items he/she has answered, nor does the difficulty of the items depend on the number and type of people who have answered them. ${ }^{17}$ Thus, all items work in the same way for all the people who complete them. ${ }^{18}$ This makes Rasch analysis different from the classical test theory (CTT), which was the most widely used measurement model in health sciences during the last century. In CTT, a person's observed score depends on the number and difficulty of the items in the test. Thus, the number and particular skills of people influence the final score in the questionnaire. ${ }^{17}$

Next, to ensure that the remaining items were independent of the patient's underlying disease and the administration route, that is, they could be generalized and that responses were not biased by any factor, we calculated differential item functioning (DIF). DIF occurs when people with the same ability have a different response probability for certain items according to the underlying disease or the administration route. ${ }^{19}$ One way to evaluate DIF is to perform a Rasch analysis on each group separately (eg, by administration route) and compare the estimates obtained by pairs of categories (eg, oral vs ostomy). A graphical representation of these comparisons shows the DIF items, that is, those that work differently in the patient group studied (outside a 95\% confidence interval). ${ }^{19}$

Finally, we quantified the fit of the remaining items with the Rasch model using infit and outfit, two statistics based on residuals, which measure the difference between observed responses and those expected by the model..$^{20}$ These measurements ensure the adequacy of the items to measure the construct of interest, in this case HRQoL, provided that the values are within the good fit range $(-2,2) .{ }^{21}$ With these statistics and their graphical representation, the items whose values were outside the range $(-2,2)$ were removed from the questionnaire as they did not present a good fit with the model.

After carrying out these steps, we obtained the final version of the NutriQoL questionnaire.

\section{Ethical aspects}

This study was conducted in accordance with the principles of the Declaration of Helsinki while also ensuring compliance with the Good Clinical Practice rules. The Spanish Agency of Medicines and Medical Devices was notified of the study, and the protocol was approved by the Clinical Research Ethics Committee at Hospital Clinic de Barcelona.

\section{Results Study population}

Experts and different groups of patients have been involved in the different study phases.

Seven experts with extensive experience in the field of HEN were invited to participate in the two focus groups.

Twenty-one patients and ten primary caregivers took part in the semistructured interviews, while 19 participants (eleven patients and eight caregivers) responded to version 1 of the questionnaire, to assess face validity and feasibility. Finally, 141 patients and 24 primary caregivers were recruited from eight Spanish hospitals to take part in the pilot study designed to perform the Rasch analysis.

\section{Questionnaire items and scoring}

During the development of the NutriQoL, the number and phrasing of the items were progressively modified according to participants' responses and the statistical analysis.

The literature review identified the main dimensions of HRQoL in patients with HEN. Dimensions included characteristics related to HEN (administration and intake), psychological aspects and activities related to daily living, social life, family and employment, and working life (Table 1). 
Table I Main dimensions of HRQoL in patients with HEN

\begin{tabular}{|c|c|}
\hline Dimension & Characteristics \\
\hline \multirow[t]{7}{*}{ HEN administration } & Administration frequency \\
\hline & Device (technology) used during \\
\hline & the product administration \\
\hline & Product presentation \\
\hline & Administration route \\
\hline & Administration time \\
\hline & Product organoleptic characteristic \\
\hline \multirow[t]{13}{*}{ Intake to HEN } & Nausea and vomiting \\
\hline & Flatulence \\
\hline & Diarrhea \\
\hline & Constipation \\
\hline & Dyspnea (depends on the \\
\hline & administration route) \\
\hline & Insomnia \\
\hline & Pain \\
\hline & Thirst \\
\hline & Pyrosis \\
\hline & Dry mouth and throat \\
\hline & Loss of appetite \\
\hline & Feeling hungry \\
\hline \multirow[t]{8}{*}{ Psychological aspects } & Self-esteem \\
\hline & Sleep \\
\hline & Body image \\
\hline & Depression/anxiety \\
\hline & Pleasure with the act of eating \\
\hline & Food self-sufficiency \\
\hline & Confidence about food \\
\hline & administration skills \\
\hline \multirow[t]{5}{*}{ Activities of daily living } & Personal hygiene \\
\hline & Getting dressed \\
\hline & Housekeeping \\
\hline & Performing leisure activities \\
\hline & Performing sports activities \\
\hline \multirow[t]{4}{*}{ Social life } & Visiting friends \\
\hline & Relationship with strangers \\
\hline & Maintaining social role \\
\hline & Traveling \\
\hline \multirow[t]{4}{*}{ Family } & Family role \\
\hline & Dependence on relatives to eat \\
\hline & Sexual activities \\
\hline & Participation in family activities \\
\hline \multirow[t]{3}{*}{ Employment and working life } & Limitations for performing \\
\hline & Job loss \\
\hline & Change of job \\
\hline
\end{tabular}

Abbreviations: HRQoL, health-related quality of life; HEN, home enteral nutrition.

Experts in HEN expressed their agreement with the dimensions identified, accepting that all of them were relevant and appropriate. As a result of the semistructured interviews, a set of expressions were considered relevant to the previously identified dimensions. These comprised the 52 items included in version 0 of the NutriQoL.

The second focus group with experts assessed the clarity of wording, frequency of occurrence, and importance of items of version 0. After evaluation, 46 items remained in the questionnaire, comprising version 1 of the NutriQoL. Finally, as a result of face validity and feasibility, three items were eliminated because of lack of clarity in comprehension.

Version 2 of the NutriQoL included 43 specific items of HEN-related HRQoL, and it had two parts: part "a" and part "b". Part "a" referred to the frequency in which patients perceived certain situations around HEN and presented five response categories: Never, Sometimes, Usually, Always, and Does not apply to my current situation. Part "b" regarded the importance that patients attached to situations mentioned in part "a", which included three response options: Nothing important, Somehow important, and Very important. Additionally, a 0-100 visual analog scale, EQ-5D ${ }^{\circledR}$-like, was included to evaluate patients' overall health status.

Version 2 of the NutriQoL was used in the pilot study designed to perform Rasch analysis. As a result of the Rasch analysis, we firstly removed eleven items from the questionnaire. To ensure that the remaining 32 items were independent of the underlying condition and administration route, the DIF analysis was performed, leading to the removal of another eleven items with DIF. Of the remaining 21 items, the four items whose values were outside the fit range $(-2,2)$ were removed from the questionnaire, leaving 17 items for the final version. A schema of the item reduction process is represented in Figure 1.

The 17 definitive items (Table 2) are divided into two dimensions: physical functioning and daily life activities (items 1, 5, 7, 8, 11, 18, 21, 22, 23, 27, 28, 34, 41, and 42) and aspects of social life (items 16, 31, and 38). These items can also be classified into positive (items 1-9) or negative (items 10-17). This classification allows for item scoring, as presented in Table 3. Each item is then scored by multiplying the individual scores of part "a" and part "b". The total scoring of the questionnaire is given by adding up the scores of the individual items from a minimum of -51 to a maximum of +51 . The patient's HRQoL may then be interpreted on the basis of the overall questionnaire score presented in Table 4.

\section{Discussion}

HRQoL is the patient-reported health outcome variable that has been the focus of the greatest interest and attention in recent years. ${ }^{4}$ Due to the chronic nature of most underlying diseases of patients receiving $\mathrm{HEN},{ }^{2}$ measuring this variable has significant value, providing information about the patient's physical, psychological, and social dimensions, improving doctor-patient communication, facilitating shared 
Table 2 Questionnaire items

\begin{tabular}{|c|c|c|}
\hline Item & Never-sometimes-always & Not important at all-important-very important \\
\hline$I^{a}$ & $\begin{array}{l}\text { With HEN, I can maintain my usual meal times (eg, breakfast, lunch, } \\
\text { dinner, supper) }\end{array}$ & For me, maintaining my usual meal times is: \\
\hline $2^{\mathrm{a}}$ & $\begin{array}{l}\text { HEN adapts to my preferences for food characteristics (eg, texture, } \\
\text { color, smell, temperature, taste) }\end{array}$ & $\begin{array}{l}\text { For me, the fact that HEN adapts to my preferences for food } \\
\text { characteristics is: }\end{array}$ \\
\hline $3^{\mathrm{a}}$ & $\begin{array}{l}\text { Since I have been receiving HEN, it is easier for me to move, } \\
\text { and I feel more agile }\end{array}$ & For me, being able to move more easily and feeling more agile is: \\
\hline $4^{\mathrm{a}}$ & $\begin{array}{l}\text { With HEN, I can continue doing my daily tasks (eg, read the } \\
\text { newspaper, cook, wash the car, clean, watch TV) }\end{array}$ & For me, being able to continue doing my daily tasks is: \\
\hline $5^{a}$ & $\begin{array}{l}\text { Since I have been receiving HEN, I perceive that my physical aspect } \\
\text { is improving (eg, I see myself as healthier) }\end{array}$ & For me, perceiving that I am looking better, physically, is: \\
\hline $6^{\mathrm{a}}$ & $\begin{array}{l}\text { I can easily obtain HEN preparations (eg, they are available } \\
\text { in pharmacies, It is easy for me to get a prescription) }\end{array}$ & For me, being able to obtain HEN preparations easily is: \\
\hline $7^{\mathrm{a}}$ & With HEN, I feel that I am well nourished & For me, feeling that I am well nourished is: \\
\hline $8^{\mathrm{a}}$ & With HEN, I have gained weight & For me, gaining weight is: \\
\hline $9^{b}$ & HEN allows me to go out with my friends & For me, being able to go out with my friends is: \\
\hline $10^{\mathrm{a}}$ & HEN harms my skin (eg, dryness, irritation, infections) & For me, harming my skin is: \\
\hline $1 I^{a}$ & HEN prevents me from sleeping well & For me, sleeping well is: \\
\hline $12^{\mathrm{a}}$ & $\begin{array}{l}\text { I worry about my body adapting to HEN and never being able to go } \\
\text { back to feeding as before }\end{array}$ & $\begin{array}{l}\text { For me, the possibility of my body adapting to } \mathrm{HEN} \text { and not } \\
\text { being able to go back to feeding as before is: }\end{array}$ \\
\hline $13^{\mathrm{a}}$ & With HEN, I miss chewing and savoring food & For me, chewing and savoring is: \\
\hline $14^{\mathrm{a}}$ & $\begin{array}{l}\text { With HEN, I experience physical discomfort due to feeding (eg, } \\
\text { feeling stomach heaviness, mouth dryness, acid reflux, regurgitation) }\end{array}$ & For me, experiencing physical discomfort due to feeding is: \\
\hline $15^{\mathrm{a}}$ & With HEN, my family keeps a closer watch over my nutrition & $\begin{array}{l}\text { For me, the fact that my family keeps a closer watch over } \\
\text { my nutrition is: }\end{array}$ \\
\hline $16^{\mathrm{b}}$ & $\begin{array}{l}\text { With HEN, I limit my activities with my friends to those not related } \\
\text { to eating }\end{array}$ & $\begin{array}{l}\text { For me, limiting my activities with my friends to those not } \\
\text { related to eating is: }\end{array}$ \\
\hline $17^{\mathrm{b}}$ & $\begin{array}{l}\text { Since I have been receiving HEN, I am more concerned about } \\
\text { my health }\end{array}$ & For me, being more concerned about my health is: \\
\hline
\end{tabular}

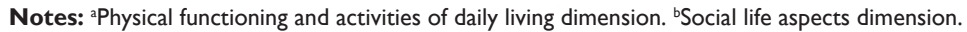
Abbreviation: HEN, home enteral nutrition.

decision-making, identifying and prioritizing problems, monitoring the impact of the disease and treatment, and in short, improving the quality of health care. ${ }^{4}$

However, there is little information about measuring HRQoL in patients receiving HEN. The few articles available mostly use generic HRQoL questionnaires that are not sensitive enough to assess HRQoL in these patients. ${ }^{6,22,23}$

The available questionnaires measuring nutrition-related HRQoL are not generalizable, irrespective of the underlying condition and administration route.

The Quality of Life related to Nutrition Status (CaVEN) questionnaire consists of 26 items that assess general health

Table 3 Questionnaire item scoring

\begin{tabular}{|c|c|c|c|}
\hline Type of item & Scoring & & \\
\hline $\begin{array}{l}\text { Part "a" with } \\
\text { positive sense }\end{array}$ & Never $=-I$ & Sometimes $=0$ & Always =I \\
\hline $\begin{array}{l}\text { Part "a" with } \\
\text { negative sense }\end{array}$ & Never $=1$ & Sometimes $=0$ & Always =-I \\
\hline $\begin{array}{l}\text { Part "b" with both } \\
\text { positive and negative sense }\end{array}$ & $\begin{array}{l}\text { Not } \\
\text { important }=1\end{array}$ & $\begin{array}{l}\text { Somehow } \\
\text { important }=2\end{array}$ & $\begin{array}{l}\text { Very } \\
\text { important }=3\end{array}$ \\
\hline
\end{tabular}

perception, physical activity, work activity, mood or emotional state, social and family relationships, and pain or discomfort on a score ranging from 26 (best perceived HRQoL) to 156 (worst perceived HRQoL). ${ }^{24}$ The reliability of the questionnaire is excellent, and it is easy to interpret. However, although it purports to assess the impact on HRQoL of interventions aimed at changing nutrition status, it does not evaluate specific aspects of HEN. ${ }^{5,6}$

The Home Parenteral Nutrition Quality of Life (HPNQOL) questionnaire consists of 48 items assessing physical, emotional, and symptomatic aspects, specifically in patients with parenteral nutrition. It contains eight functional scales

Table 4 The NutriQoL ${ }^{\circledR}$ overall score and HRQoL interpretation

\begin{tabular}{ll}
\hline NutriQoL ${ }^{\circledR}$ score & HRQoL interpretation \\
\hline Between -51 and -30 & Very bad \\
Between -29 and -11 & Bad \\
Between -10 and +10 & Regular \\
Between +11 and +31 & Good \\
Between +32 and +51 & Very good \\
\hline
\end{tabular}

Abbreviation: HRQoL, health-related quality of life. 
and nine symptom scales. The functional scales assess overall health, ability to holiday/travel, coping, physical function, ability to eat or drink, employment, sexual function, and emotional function, while the symptom scales assess body image, immobility, fatigue, sleep patterns, gastrointestinal symptoms, pain, stoma management/bowel movements, financial aspects, and weight. However, it does not evaluate the same aspects in patients receiving HEN, and therefore does not make it possible to reliably estimate its influence on the HRQoL in these patients. ${ }^{25}$

Finally, the Quality of Life in Enteral Feeding (QOL-EF) questionnaire is a specific instrument for assessing the impact of enteral nutrition tubes in patients with head and neck cancer. ${ }^{7,26}$ It consists of 20 items with scores between 20 (best HRQoL) and 100 (worst HRQoL). The purpose of designing this questionnaire was to produce an instrument that would be useful in patients from different cultures, including Chinese people where there is a high prevalence of this disease. However, most of the participants included in the development and validation were women of Chinese origin, which may affect its sensitivity in aspects of other cultures or in male patients. Additionally, it was designed to be used in conjunction with other specific HRQoL questionnaires for patients with head and neck cancer. ${ }^{7}$ Given that this instrument only measures how the enteral nutrition tube affects HRQoL, and that the underlying diseases and the administration route of HEN differ between patients, ${ }^{1}$ this questionnaire does not make it possible to study the relationship between HEN and HRQoL.

All this highlights the need for an instrument such as the NutriQoL questionnaire, a specific questionnaire to measure the HRQoL of patients receiving HEN, regardless of the underlying disease or the administration route.

To develop the NutriQoL questionnaire, we have followed the steps included in the US Food and Drug Administration guidelines, ${ }^{27}$ using an iterative process for obtaining and modifying items. Additionally, we used the Rasch analysis to reduce the number of items, ensuring that the estimates of the person parameters and the questionnaire items were independent, resolving the limitations of CTT. ${ }^{17}$

The next step in the NutriQoL development is its psychometric validation to ensure validity, reliability, sensitivity to changes in patients' health status, and MCID, for which a specific study has been designed.

Moreover, an MCID will be provided, which will facilitate the identification of a significant change in the patient's and the clinician's points of view during follow-up in routine clinical practice. ${ }^{28}$ These properties will enable clinicians to assess the HRQoL of patients receiving HEN and amend the treatment regime based on the results of their assessment.

However, we anticipate that the NutriQoL questionnaire's sensitivity to changes will be low to moderate. This is because the measurements will be made over a total evaluation period between visits that is shorter than expected, and also in patients receiving $\mathrm{HEN}$, where the underlying disease is usually a chronic problem, and observed changes in outcome variables are usually evident over longer periods. ${ }^{2,29}$ The questionnaire's sensitivity to changes will have to be calculated again using data from patients in routine clinical practice.

In conclusion, as a result of the development of the NutriQoL, practitioners will have a unique and reliable tool to assess HRQoL in HEN patients, regardless of the underlying disease or the administration route.

\section{Acknowledgments}

The abstract of this paper was presented at the International Society for Pharmacoeconomics and Outcomes Research 17th Annual European Congress (Amsterdam, the Netherlands) on November 2014 as a poster with interim findings. The poster's abstract was published in "Value in Health" Vol 17, Issue 7, A518 (http://www.valueinhealthjournal.com/article/ $\underline{\mathrm{S} 1098-3015(14) 03541-4 / \mathrm{pdf})}$ ) and A575 (http://www. sciencedirect.com/science/article/pii/S1098301514038650).

Nestlé Health Science sponsored the study.

\section{Disclosure}

The authors MC Cuerda, A Apezetxea, L Carrillo, F Casanueva, F Cuesta, JA Irles, and MN Virgilli state that they have no conflicts of interest. M Layola works at Nestlé Health Science. L Lizan works for an independent research organization (Outcomes'10, S.L.) which has received fees for its contribution to the development and coordination of the original research project and to the writing of this manuscript.

\section{References}

1. Ministry of Health, Social Services and Equality. Guia descriptiva de la prestación con productos dietéticos del Sistema Nacional de Salud [Provision descriptive guide with SNS dietetic products]. 2015. Available from: http://www.msssi.gob.es/profesionales/prestacionesSanitarias/ publicaciones/docs/042015_GuiaProdDiet_2ed.pdf. Spanish.

2. Schneider SM, Raina C, Pugliese P, Pouget I, Rampal P, Hebuterne P. Outcome of patients treated with home enteral nutrition. JPEN J Parenter Enteral Nutr. 2001;25(4):203-209.

3. McNamara EP, Food P, Kennedy NP. Home tube feeding: an integrated multidisciplinary approach. J Hum Nutr Diet. 2001;14(1):13-19.

4. Lizán Tudela L. La calidad de vida relacionada con la salud [Healthrelated quality of life]. Aten Prim. 2009;41(7):411-416. Spanish.

5. Bannerman E, Pendlebury J, Phillips F, Ghosh S. A crosssectional and longitudinal study of health-related quality of life after percutaneous gastrostomy. Eur J Gastroenterol Hepatol. 2000;12(10):1101-1109. 
6. Jordan S, Philpin S, Warring J, Cheung WY, Williams J. Percutaneous endoscopic gastrostomies: the burden of treatment from a patient perspective. J Adv Nurs. 2006;56(3):270-281.

7. Stevens CS, Lemon B, Lockwood GA, Waldron JN, Bezjak A, Ringash J. The development and validation of a quality of life questionnaire for head and neck cancer patients with enteral feeding tubes: the QOL-EF. Support Care Cancer. 2011;19(8):1175-1182.

8. Santana MJ, Feeney D. The importance of measuring health-related quality of life. IHE report. Edmonton: Institute of Health Economics; 2008. Available from: http://ihe.ca/publications/the-importance-ofmeasuring-health-related-quality-of-life. Accessed January, 2011.

9. Kitzinger J. Qualitative research. Introducing focus group. BMJ. 1995;311(7000):299-302.

10. Cohen D, Crabtree B. Qualitative research guidelines project. 2006. Available from: http://www.qualres.org/HomeSemi-3629.html. Accessed May, 2011.

11. Webb SM, Prieto L, Badia X, et al. Acromegaly Quality of Life Questionnaire (ACROQOL) a new health-related quality of life questionnaire for patients with acromegaly: development and psychometric properties. Clin Endocrinol (Oxf). 2002;57(2):251-258.

12. Badia X, Webb SM, Prieto L, Lara N. Acromegaly Quality of Life Questionnaire (AcroQoL). Health Qual Life Outcomes. 2004;2:13-18.

13. Carvajal A, Centeno C, Watson R, Martinez M, Sanz Rubiales A. Cómo validar un instrumento de medida de la salud? [How is an instrument for measuring health to be validated?]. An Sist Sanit Navar. 2011;34(1): 63-72. Spanish.

14. Patrick DL, Burke LB, Gwaltney CJ, et al. Content validity. Establishing and reporting the evidence in newly developed patient reported outcomes (PRO) instruments for medical product evaluation: ISPOR PRO Good Research Practices Task Force Report: Part 2. Assessing respondent understanding. Value Health. 2011;14(8):978-988.

15. Linacre JM. Sample size and item calibration stability. Rasch Measure Trans. 1994;7:28.

16. Hagquist C, Bruce M, Gustavsson P. Using the Rasch model in nursing research: an introduction and illustrative example. Int J Nurs Stud. 2009;46(3):380-393.

17. Prieto L, Alonso J, Lamarca R. Classical test theory versus Rasch analysis for quality of life questionnaire reduction. Health Qual Life Outcomes. 2003;1:27.

18. Dols Calatayud O, Lopez Pina JA. Análisis psicométrico de la subescala manipulación de objetos de la escala peabody de desarrollo motor segunda edición (PDMS-2) con el modelo Rasch [Psychometric analysis of the subscale object manipulation of the peabody developmental motor scale-second edition (PDMS-2) with the Rasch model]. Fisioterapia. 2011;33(4):145-156. Spanish.
19. Prieto G, Delgado A. Análisis de un test mediante el modelo Rasch [Analysis of a test using Rasch model]. Psicothema. 2003;15(1):94-100.

20. Zumbo BD. Three generations of DIF analyses: considering where it has been, where it is now, and where it is going. Lang Assess Q. 2007; 4(2):223-233.

21. Cadavid N, Delgado AR, Prieto G. Construcción de una escala de depresión con el modelo de Rasch [Building a depression scale using Rasch model]. Psicotherma. 2007;19(3):515-551. Spanish.

22. Linacre JM. What do infit and outfit, mean-square and standardized mean? Rasch Measure Trans. 2002;16:878

23. Schneider SM, Pouget I, Staccini P, Rampal P, Hebuterne X. Quality of life in long-term home enteral nutrition patients. Clin Nutr. 2000; 19(1):23-28.

24. Wanden-Berghe C, Nolasco A, Sanz-Valero J, Planas M, Cuerda C; Group NADYA-SENPE. Health-related quality of life in patients with home nutritional support. J Hum Nutr Diet. 2009;22(3):219-225.

25. Wanden-Berghe C, Martin Rodero H, Guardiola Wanden Berghe R, Sanz Valero J, Galindo-Villardón P. Cuestionario de calidad de vida relacionado con el estado nutricional [Quality of life questionnaire related to nutritional status]. Nutr Hosp. 2012;27(6):1876-1885. Spanish.

26. Reddy P, Malone M. Cost and outcome analysis of home parenteral and enteral nutrition. JPEN J Parenter Enteral Nutr. 1998;22(5): 302-310.

27. US Department of Health and Human Services Food and Drug Administration. Guidance for industry. Patient reported outcome measures: use in medical product development to support labeling claims. 2009. Available from: http:/www.fda.gov/downloads/Drugs/.../Guidances/ UCM193282.pdf. Accessed July, 2015.

28. Revicki D, Hays RD, Cella D, Sloan J. Recommended methods for determining responsiveness and minimally important differences for patient-reported outcomes. J Clin Epidemiol. 2008;61(2):102-109.

29. Husted JA, Cook RJ, Farewell VT, Gladman DD. Methods for assessing responsiveness: a critical review and recommendations. J Clin Epidemiol. 2000;53(5):459-468.
Patient Preference and Adherence

\section{Publish your work in this journal}

Patient Preference and Adherence is an international, peer-reviewed, open access journal that focuses on the growing importance of patient preference and adherence throughout the therapeutic continuum. Patient satisfaction, acceptability, quality of life, compliance, persistence and their role in developing new therapeutic modalities and compounds to optimize

\section{Dovepress}

clinical outcomes for existing disease states are major areas of interest for the journal. This journal has been accepted for indexing on PubMed Central. The manuscript management system is completely online and includes a very quick and fair peer-review system, which is all easy to use. Visit http://www. dovepress.com/testimonials.php to read real quotes from published authors. 